\title{
Dentifrice Gel Dosage Form
}

National Cancer Institute

\section{Source}

National Cancer Institute. Dentifrice Gel Dosage Form. NCI Thesaurus. Code C42906.

A gel intended for use in the oral cavity to clean the teeth and maintain oral hygiene. 